The University of Akron

\title{
IdeaExchange@UAkron
}

Proceedings from the Document Academy

University of Akron Press Managed

January 2016

\section{Using Heider's Epistemology of Thing and Medium for Unpacking the Conception of Documents: Gantt Charts and Boundary Objects}

\author{
Sebastian K. Boell \\ The University of Sydney Business School, sebastian.boell@sydney.edu.au \\ Florian Hoof \\ Goethe Universität Frankfurt, hoof@tfm.uni-frankfurt.de
}

Please take a moment to share how this work helps you through this survey. Your feedback will be important as we plan further development of our repository.

Follow this and additional works at: https://ideaexchange.uakron.edu/docam

Part of the Epistemology Commons, Library and Information Science Commons, Management Information Systems Commons, and the Other Film and Media Studies Commons

\section{Recommended Citation}

Boell, Sebastian K. and Hoof, Florian (2015) "Using Heider's Epistemology of Thing and Medium for Unpacking the Conception of Documents: Gantt Charts and Boundary Objects," Proceedings from the Document Academy: Vol. 2 : Iss. 1 , Article 3.

DOI: https://doi.org/10.35492/docam/2/1/3

Available at: https://ideaexchange.uakron.edu/docam/vol2/iss1/3

This Conference Proceeding is brought to you for free and open access by University of Akron Press Managed at IdeaExchange@UAkron, the institutional repository of The University of Akron in Akron, Ohio, USA. It has been accepted for inclusion in Proceedings from the Document Academy by an authorized administrator of IdeaExchange@UAkron.For more information, please contact mjon@uakron.edu, uapress@uakron.edu. 


\section{Introduction}

Documents are an essential and integrative aspect of virtually all aspects of modern life. Documents are used for conducting business, for developing policy, for education, for making decisions, and in many other contexts. Documents are not only the "primary mechanism for conducting business" (McNurlin and Sprague 1998, p. 455) but more generally written records are related to all forms of social structure (Freeman and Maybin 2011, p. 156).

In the literature two broad approaches for conceptualizing documents can be observed. The first approach takes documents as things, physical carriers, which are containers for conveying content. The second approach takes documents as a medium that connects different spheres or actors. For instance, one can argue that the content of an electronic document is determined by the technology that is used to create, store and reproduce this document. In contrast, others would follow a more hermeneutic tradition, arguing that the content of a document is determined by the fact that a document is relevant and interpreted within a particular social context. Clearly both positions are valid and it is therefore important to understand when documents are perceived either as being a thing or as being a medium. However, currently there is no clear understanding of how both understandings of documents are related.

We therefore engage with the question: What characteristics of a document are relevant for perceiving documents as thing or medium? To engage with this overarching research interest we draw from concepts developed in the context of media theory to define and describe phenomena of mediation, transmission and perception. In particular we investigate how Fritz Heider's (1926) epistemology of thing and medium may be used for developing an understanding of documents as thing and medium. According to this account documents can be perceived as things with certain features. In contrast, if a document is perceived as a medium one no longer perceives the document itself, but other things that can be seen through the document. As claimed by Heider the difference between thing and medium is determined through the internal granularity of a document. We therefore offer an explanation for the bifurcation of documents as containers for content and mediators among social actors. In particular we have the following research aims:

a) to investigate how documents are conceptualized as things and medium

in the literature;

b) to exemplify how documents can simultaneously be perceived as a thing and a medium;

c) and to develop a conceptualization of the perception of documents as thing and medium based on Heider's (1926) epistemology.

Using Gantt Charts as an example of documents used for managing work activities, we demonstrate how Heider's epistemology can be applied to better understand the dual function of documents in organizations where they are used both as containers for content and as vehicles for communication among different stakeholders. This is important as it provides an explanation for how individual stakeholders perceive documents. Importantly, how organizational 
member perceive documents enables and restricts the ability of individuals to act within their organization. The collective perception of documents therefore shapes the wider practices an organization is engaged in, as things become visible, hidden, important, neglected, disregarded, requiring action, demanding attention and so on. Documents, as "written records" (Yates 1989, p. 164) therefore provide the foundation for an organization's ability to see its internal and external environment and to act within and upon it.

\section{The Concept of Document}

Looking at how documents are conceptualized in the literature (Boell and Cecez-Kecmanovic 2015) two broad streams of conceptions of documents can be identified (Buckland 2014). A first stream in the literature predominantly understands documents as things - tangible objects with specific features. A second stream predominantly looks at documents as medium - facilitators of communication across different groups of stakeholders. Both streams are summarized in an ideal typical way in table 1.

Conceptions of documents as things emphasize documents as objects that can be understood in their own right. That is, documents are seen as having certain material properties, such as a genre, a creator or a specific set of words that are contained in them. Such a conception of documents is, for instance, often underlying information retrieval approaches where documents are understood in terms of properties that are objectively contained in a document from which they can be extracted and made available for document retrieval. One way for unpacking the concept of document is thus to conceptualize a document as a thing that has certain 'objective' properties. One example of such a conceptualization is visualized in figure 1. According to this example documents can be described in three different ways: documents are of a particular type or genre, documents can be described in terms of metadata about them, and finally documents contain a particular content. Types of documents are, for instance, letters, memos, invoices, reports, meeting notes, polices, timetables, presentations, budgets, and so on. Metadata are details about a document, such as the author/creator, the creation time and date, or an intended readership. And finally content is what is actually contained in a document, such as the text contained in a letter. 


\begin{tabular}{|c|c|c|}
\hline \multicolumn{3}{|c|}{ Table 1: Overview of conceptions of documents } \\
\hline Conception & Exemplary quotes & $\begin{array}{l}\text { Assumptions } \\
\text { about } \\
\text { documents }\end{array}$ \\
\hline $\begin{array}{l}\text { Documents } \\
\text { as 'things' }\end{array}$ & $\begin{array}{l}\text { "[Documents] are bits of the material } \\
\text { world-clay, stone, animal skin, plant } \\
\text { fiber, sand, that we've imbued with the } \\
\text { ability to speak." (Levy } 2001, \text { p. 23) } \\
\text { "none of what might be called } \\
\text { traditional approaches to documentation } \\
\text { theorize documents as anything other } \\
\text { than 'things' created and set in motion } \\
\text { by human actors." (Prior 2008, p. 833). } \\
\text { "The word Document can be used to } \\
\text { refer to the physical 'container' of the } \\
\text { Linguistic text. [...] Documents are } \\
\text { physical, material objects that can be } \\
\text { held in hand." (Shillingsburg 1991, p. } \\
\text { 54) }\end{array}$ & $\begin{array}{l}\text { - Are carriers of } \\
\text { content } \\
\text { - Exist } \\
\text { objectively } \\
\text { (tangible) } \\
\text { - Have certain } \\
\text { characteristics } \\
\text { and features } \\
\text { - Are created by } \\
\text { an author } \\
\text { - Provide for a } \\
\text { certain } \\
\text { stability }\end{array}$ \\
\hline $\begin{array}{l}\text { Documents } \\
\text { as 'medium' }\end{array}$ & $\begin{array}{l}\text { "Documents are produced for specified } \\
\text { and specifiable others and their } \\
\text { "sharedness' is a function of their } \\
\text { sociality." (Hughes and King, 1993, p. } \\
\text { 156). } \\
\text { "documents are not simple, physical } \\
\text { embodiments but are equally defined by } \\
\text { the ways they are understood." (Lund } \\
2009, \text { p. 31) } \\
\text { "The document itself is a practised } \\
\text { thing [...] a conduit or corridor, } \\
\text { something through which other things } \\
\text { (power, meaning) flow." (Freeman and } \\
\text { Maybin 2011, p. 165) }\end{array}$ & $\begin{array}{l}\text { - Are vehicles of } \\
\text { discourse } \\
\text { - Exist } \\
\text { differently for } \\
\text { different actors } \\
\text { - Have readers } \\
\text { and authors } \\
\text { - Are flexible } \\
\text { adaptable to } \\
\text { different } \\
\text { contexts }\end{array}$ \\
\hline
\end{tabular}




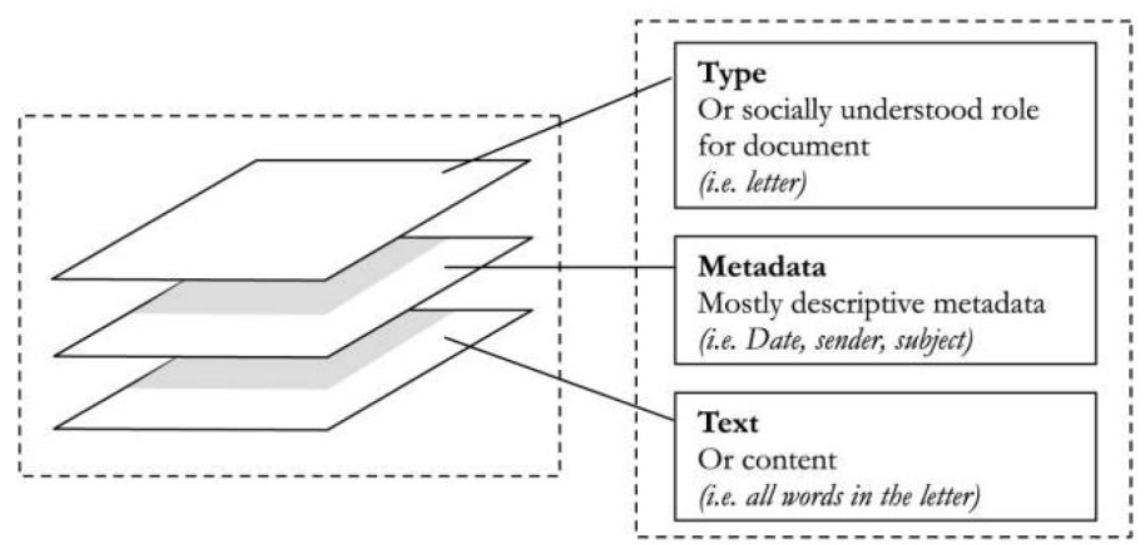

Figure 1: Conception of documents as type, metadata, and content (Adapted from Forbes-Pitt 2006)

Unpacking the concept of documents in this way, the content of documents is seen as an objective entity contained within a document when it is created by an author. That is the content of a document contains a specific collection of signs, such as letters, words and sentences in a way that is independent of a particular observer. Documents are stable entities that can be analyzed in their own right as their content is understood to be inscribed into a document during its creation by an author.

However, others have highlighted that documents are also devices that act as bridges, gateways, connectors, or intermediaries between different groups of stakeholders. A document is therefore understood as a medium that conveys a message across disciplinary or divisional boundaries as it connects groups acting within different professional spheres. For instance, medical forms serve as 'boundary objects' between different groups of stakeholders, such as doctors, health insurances, nurses and patients (Bowker and Star 1999). In this respect documents are standardization devices that because of their abstract forms as lists or forms act as a means to stabilize different social systems, such as the health system (Figure 2). One important feature of documents as boundary objects is that their use is not predetermined but that their use can be 'tailored' to different needs across different professional spheres as they are used other than initially intended in a different professional sphere. In the health system, forms and labels provide a common ground for communication across different domains. This use of documents is to be seen not as problematic but instead as a productive principle that enhances flexibility and guarantees a low level threshold for interaction across different professional spheres. Forms enable nurses, physicians, or laboratory staff to understand a particular case in terms of their individual domain, while at the same time ensuring that all domains share an understanding about the case they are working on. 


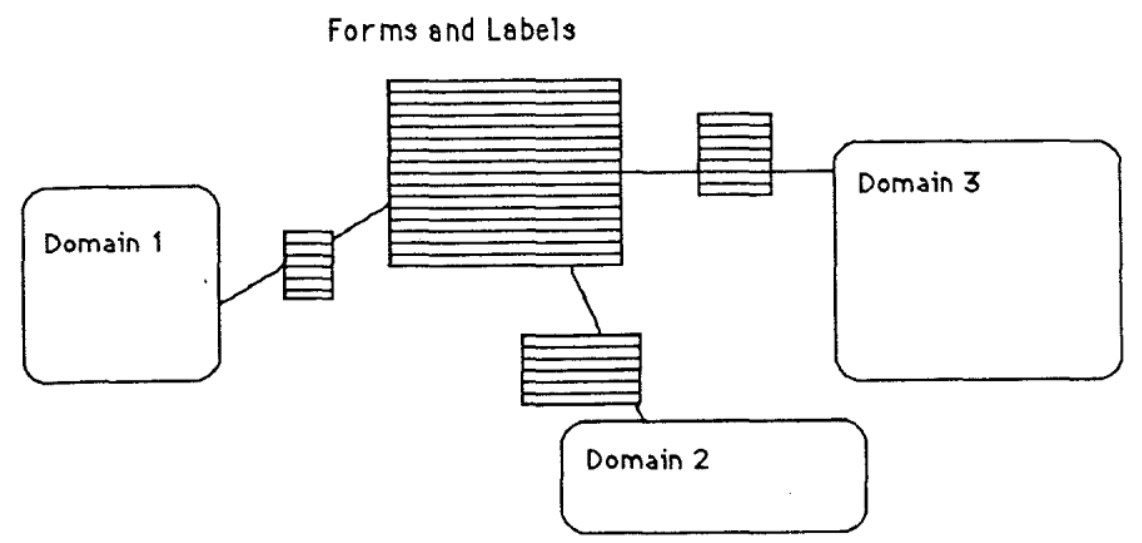

\section{Figure 2: Boundary objects conception of documents as medium (Adapted from Star 1989)}

Documents are integrative to virtually every aspect of life, nevertheless, the very notion of what a document is is conceptualized differently in the literature. Our review highlights an observation made before (Buckland 2014; Lund 2009), namely, that different conceptions of documents assume either a thing-like or a medium-like character of documents. Importantly, both approaches for understanding documents are based on different assumptions that bring to the fore different aspects of what a document is. This requires a more substantial engagement with the problem of how documents are at the same time 'things' with properties and 'medium' that facilitate communication across different domains. We therefore seek to address the following research question: How can we understand at an epistemological level the perception of documents as either a thing or a medium?

\section{Fritz Heider's Epistemology}

We now introduce Fritz Heider's (1926) epistemology which we will use below for understanding the dual appearance of documents as thing and medium. Heider's concepts have been used in context of sociological system theory (Luhmann 1990) and more recently were applied to media theory (Baecker 2002; Hoof 2015a, 2016). We apply Heider's distinction between different modes of perception to clarify when things can be described as a medium and when not.

Heider's approach is grounded in perception and his later work (Heider 1944) has influenced perceptual psychology, for instance, Gibson's (1977) conception of affordance. In thing and medium Fritz Heider (1926) is interested in the problem of how things in the world are able to convey information about other things in the world. He argues that if a 'thing' - such as a sheet of glass or air - convey information about other things in the world, this sheet of glass becomes a medium. As a medium a sheet of glass is no longer perceived as a thing in itself, instead it becomes a vehicle through which we perceive other 
things. The sheet of glass becomes 'invisible' and we perceive instead the weather outside. Heider (1926), therefore, provides an account of what constitutes a medium - things through which we can perceive other things.

But Heider (1926) also provides an account for how it is possible for a medium to convey information about 'things' that exist in the world, as clearly not everything is equally well suited to convey information about other things. According to Heider what sets things and medium apart is that a thing is uniform, whereas a medium is multiform. When a thing, say a stone is pushed into one direction all aspects of the stone are uniformly moving into the same direction, we therefore perceive the stone as being a thing. In contrast, a medium is multiform as it can be described as constituted of independent or only loosely connected elements. For instance, when pushed, air is not moving uniformly into one direction but the many elements of which air consists are moving into vastly different directions. For Heider one central quality of a medium is therefore their ability to be multiform. However, what enables a medium to convey a message about things is not multiformity as such, but its ability to create false impressions of uniformity. Because a medium being multiform it can be in many different states, however, when many of the multiform aspects of a medium are moving together they create a false impression of unity and therefore enable a medium to convey information about something else. Thus if different elements of air are simultaneously moving into one direction it is not air that is perceived, but the source that is creating a false impression of unity in the air. Thus air moving into any direction is not commonly perceived as noise. However, when air is moving in a particular direction and thus creates a false impression of uniformity air become a medium for sound waves.

For this reason a sheet of glass can be a medium as light can pass through it different ways - so to speak the glass is multiform when it comes to light going through it. When we now perceive a particular light pattern through a sheet of glass the particular composition of that pattern is not perceived as the consequence of the glass itself, but due to things that create a false impression of unity. That is, we perceive light in a particular way but the 'pattern' we perceive is not ascribed to the medium but to things behind this medium that create this pattern.

According to Heider a medium has a certain level of 'multiformity' in regard to an aspect that is conveyed through it. From this follow two things. Firstly, the multiformity or 'granularity' in regard to something that is conveyed determines the quality of a thing for being a medium for something else. The less transparent a sheet of glass is the more we will ascribe a certain light pattern to the glass rather than to something else that is behind the glass. As the sheet of glass becomes more and more visible as a thing its ability to be a medium for light waves diminishes more and more. Secondly, the ability for something to be a medium for some aspect will depend on its ability to be multiform regarding this aspect. Again the ability of a sheet of glass to be a medium for light requires a different type of multiformity than its ability to be a medium for noise. While the former requires light waves to be conveyed through the sheet 
of glass in multiple different ways the later requires sound waves to travel through the sheet of glass in different ways. What constitutes multiform will therefore depend on the things for which something is sought for as a medium.

\section{Gantt Charts}

So what does it mean if we apply Heider's distinction between thing and medium for conceptualizing documents? To further explore this we chose Gantt charts (Figure 3) as an example for investigating aspects of documents as thing and medium. While Gantt charts were first developed by Henry L. Gantt, in context of scientific management at the end of the $19^{\text {th }}$ century (Hoof 2015a, pp. 110-128), they are still widely used for scheduling, allocation, and synchronization in the planning of workflows and project management (Yakura 2002). Gantt charts, therefore, provide a good case example of a document that is widely used in organizations for more than over a century.

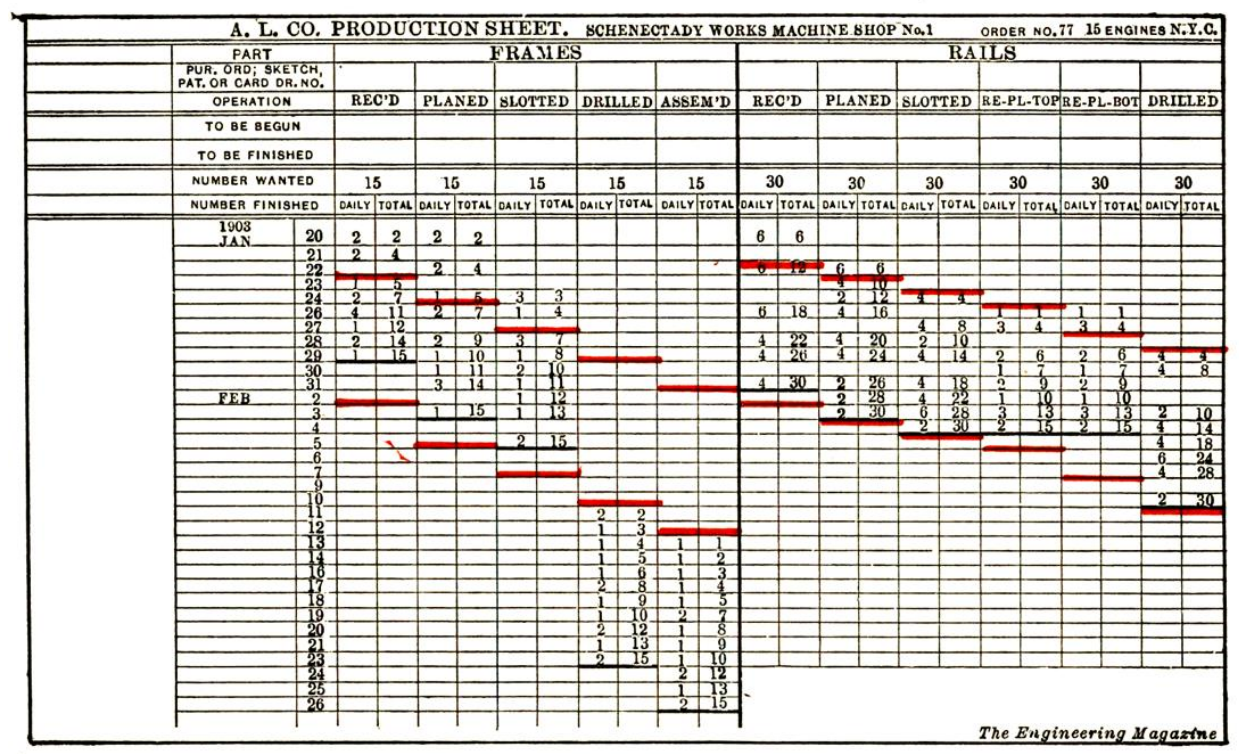

Figure 3: Example of Gantt Chart for the Schenectady Works Machine Shop (Adapted from Gantt 1903)

Gantt Charts are used as a means to jointly coordinate and steer interdependent tasks in an organization, for instance, the manufacturing of a product in several stages. Gantt charts provide a visual representation on two axis, where one axis represents time and the other axis represents a matter of managerial interest, commonly things such as: activities, units produced, or budget expenditures. Figure 3 provides one such example where we see (on the vertical axis) a time frame of one and a half months segmented into single days visually representing a production schedule of items to be produced on each day. In this case from 1903 - the first Gantt charts ever published - the matter of managerial interest are frames and rails that are to be produced at the Schenectady Works Machine Shop specialized in producing steam trains. On the 
horizontal axis, from left to right, the Gantt chart lists operations that have to be fulfilled in a specific order for producing a certain item - in this example frames and rails. The purpose of the chart is thus to coordinate these different production steps in the right order and the most efficient way. The latest date when a particular task has to be finished so that another following task can start without delay is marked by a so-called danger line (Gantt 1919, p. 274). If operations are delayed and one of the danger lines is crossed then bigger consequences for the organization are expected, as a delay will no longer effects one particular operation but the whole array of operations that depend on a preceding operation. Danger lines in this early Gantt charts define what later became known as critical path - the point in time beyond which delays in one activity would delay all other steps of a production process (Hoof 2015a, pp. 119-121). Therefore, it is no surprise that Gantt charts were first used in industries that were highly prone to malfunctioning, such as the steel industry.

Historically, Gantt charts can be described as a mechanism that amongst others was used by management to exercise control through communication (Yates 1989). Gantt charts are not a unique innovation but part of a wider written records based management system that came into use to maintain control in multiunit enterprises that were affected by the so-called crisis of control (Beniger 1986; Chandler 1977). Crisis of control is commonly used to describe coordination problems that emerged in fast growing corporations after 1860 . While being specific Gantt charts are therefore also generic, as similar documents, such as magnetic time planning systems or harmonographs (Adamiecki 1909) are continuously used in industrial organizations since the 1890ies (Marsh 1975). Gantt charts, as a genre of documents, are therefore well established withstanding technological as well as social and economical changes as they are still used in the original form as a Gantt chart or as part of network planning techniques such as the Program Evaluation and Review Technique (PERT) (Malcolm et al. 1959; Kelley and Walker 1959). Furthermore, Gantt charts are a document that is used by and is situated between heterogeneous groups of people in industrial organizations. Upper management, middle management as well as workers on the factory floor are using Gantt charts. While they are all working with an identical Gantt chart, the chart is for them a document with vastly different meanings. Thus, Gantt charts have been analyzed and described as temporal boundary objects (Yakura 2002) and media boundary objects (Hoof 2011; 2015b) due to their ability, to not only synchronize different social worlds, but also as they offer flexibility and a low level threshold for engagement among heterogeneous groups of organizational actors.

\section{Documents as 'Thing and Medium'}

We now use the example of Gantt charts to illustrate how Heider's (1926) epistemology can be used for understanding how documents are perceived both as thing and medium. Firstly, Gantt charts can be understood in terms of Heider's concept of thing: Gantt charts have a specific layout that is used for planning diverse tasks and to synchronize them. In our example (Figure 3 ) the 
Gantt chart is used for tracking the production of parts on a day-by-day basis. Gantt charts as things therefore display figures that represent and organize production in a standardized way. Gantt Charts are used to create and circulate specific data that is organized in columns and rows. Top management, foremen, and workers in the workshop all refer to data represented in these charts. Gantt charts thus depict a specific logic of industrial production where everything that does not fit into the logic of these charts cannot be displayed and is left out. In this sense Gantt charts as 'things' are uniform as they display production figures and data in a particular way that is determined by the character of a Gantt chart.

Secondly, Gantt charts can also be understood and described as a medium: Besides their character to document and making data accessible, Gantt charts are also a medium that enables to perceive things through them. For workers Gantt charts enable them to understand that their work is perceived predominantly in terms of productivity by their managers and foreman. For foremen Gantt charts help them to keep track of what is going on in their workshop as Gantt charts extend their ability to react to delays or breakdowns by rescheduling work steps to avoid further coordination problems. Finally, management will look at Gantt charts if there is an issue that has to be solved, for example, recurring problems noticed in a particular section of the factory. When Gantt charts are used to understand other things through them, they become transparent as the attention is no longer on the Gantt chart as such but at what can be perceived through the chart. To achieve this function Gantt charts are multiform as at they are flexible enough to become a medium that enables to see other 'things' through them.

However, according to Heider the ability for something to be a medium will depend on how multiform a medium is regarding a particular purpose. In this sense are Gantt charts - or any other document - not a neutral medium. The ability of a Gantt chart to be a medium for perceiving things is restricted by its 'granularity' in the same way as a sheet of glass is restricted in its ability to convey sound waves. When a production schedule is perceived through a Gantt chart the thingness of the Gantt chart becomes invisible to workers, foremen, or managers and therefore what also becomes invisible is how the uniformity of the Gantt chart restricts what can be seen. The induction of a new member into the workforce, a heat wave with extreme temperatures, farewell of a colleague into retirement, or poor quality of new replacement parts are invisible when production is looked at through Gantt Charts. As a medium Gantt charts therefore stabilize a particular managerial discourse and regime of control as Gantt charts have inscribed into them a particular ability for perceiving the world through them.

Our example of Gantt charts thus highlights the relevance of different aspects when documents are perceived as thing or as medium. Documents as things are uniform, having a thing like character with concrete meaning, whereas documents as medium are multiform. Importantly, perception of documents is not fixed to be either a thing or a medium as one can turn into the other and vice versa. Employing Heider's epistemology for understanding 
documents is thus useful as it highlights the relational characteristic of documents being a priory neither a thing nor a medium. Instead the perception of a document as thing or medium is only emerging in relation to a particular purpose. Depending on a situation a Gantt chart can be both a thing, for instance, when we discuss how such charts are designed; or a medium, when a Gantt chart is used as a communication device between managers, foreman and workers. Heider's epistemology can thus be used to understand how documents change from being perceived as a medium into a thing and back again. Documents as things are uniform enabling them to have a concrete and fixed meaning within a particular professional sphere as they restrict how a document can be interpreted. Documents as medium are multiform with the ability to create false impressions of uniformity across different professional spheres.

This understanding of documents as enabling and restricting the ability to perceive the world has further implications as Heider's epistemology can be used for understanding how documents appear in organizations more widely. For instance, existing approaches to documents as boundary objects focus on the relational and changing character of documents as intermediaries (Bowker and Star 1999; Star and Griesemer 1989; Star 1989; 2010). These approaches have highlighted that documents are devices that act as bridges, gateways, connectors, or intermediaries between different groups of stakeholders. Documents are therefore understood as a medium that connects groups acting within different professional spheres, as they convey messages across disciplinary or divisional boundaries. For instance medical forms serve as boundary objects between different groups of stakeholders, such as doctors, health insurances, nurses and patients (Bowker and Star 1999).

Heider now offers an approach for understanding how documents can become boundary objects as they offer a particular balance between uniformity and multiformity - between thing and medium. The ability of a document to act as a boundary spanning object is due to its limited medium character as it is more uniform than other types of documents. Generally a medium is invisible as thing, as the attention is on the 'things' that are seen through the medium. As a clear sheet of glass acts as a medium for light waves we no longer perceive the glass but instead we see other things through the glass. That is the medium disappears from perception. This is also the case for documents as medium as the thing character of the document itself disappears, things are seen through the document. However, as boundary objects act as medium between different groups of stakeholders they cannot completely disappear and become a transparent medium. Instead they also need to be perceived as a thing that can be interpreted and understood. For example, Star and Griesemer (1989) argue that an ideal type is a boundary object because it is locally adaptable due to its level of abstraction: "Boundary objects are objects which are both plastic enough to adapt to local needs and the constraints of the several parties employing them, yet robust enough to maintain a common identity across sites," (p. 393). Using Heider we can now say that a boundary object is multiform 
enough to act as a medium across different disciplinary boundaries but also uniform enough so that it can be perceived as a similar thing by different actors.

Another example to demonstrate how Heider can be used to make sense of how documents are perceived is when documents are digitized. When a document is digitized it not only changes as a thing, but also as a medium. That is the digitized object has a different internal structure affecting its granularity and therefore its ability to be perceived as a thing or medium. When a document is digitized it becomes more multiform as it is more readily accessible and can be easily compared to other documents in a way that was not possible before. Therefore the document changes as a medium as other and possibly more things become visible through it. At the same time the document loses some of its thingness, it becomes more elusive and less obvious that the document only offers a particular view onto the world. As the document disappears one can come to believe that what is seen through the document as medium is what there is. However, Heider would caution such an understanding as what can be seen through a document as medium always needs to be understood as being shaped by the granularity of the document itself.

\section{Conclusion}

Documents are integrative to virtually every aspect of life as they are used for communication across space, time, and different domains. To shed light on the question of how documents can be perceived, we did three things:

Firstly, we investigated how documents are conceptualized in the literature. Our review of the literature revealed that two conceptions of documents are prevalent in the literature: one that understands documents as physical things, carriers of inscriptions that have meaning, and another understanding documents as medium that allow one to seen other things through documents. Our review is thus aligned with a review of document theory by Lund (2009), confirming that different conceptions of documents highlight either the thing-like or medium-like character of documents.

Secondly, we used Heider's (1926) epistemology to develop a conceptualization of the perception of documents as thing and medium. According to this conceptualization a thing is uniform, whereas a medium is multiform. The ability of something to act as a medium for something else is determined by its internal granularity regarding an aspect that is conveyed. Thus when a document is perceived as a medium it is multiform in a way that enables the document to 'disappear' and reveal other things that are seen through the medium. Heider's (1926) epistemology therefore offers a novel way for conceptual understanding of how documents are always dual as they are perceived as thing and medium.

Thirdly, we used Gantt charts to exemplify how documents are simultaneously perceived as a thing and a medium. Gantt charts have a strong thing character as they are structured in a particular way that restricts their ability for conveying messages. Using Heider's conception we can thus say that the ability of a Gantt chart to act as a medium is both enabled and restricted by 
its internal granularity. Gantt charts can act as boundary spanning objects precisely because they have a limited granularity that restricts their multiformity. This 'thingness' of Gantt charts contributes to them being usable as boundary object precisely because they cannot be a medium for different things other than matters of managerial interest over time.

This paper therefore offers a novel conception of how documents can be perceived as thing and medium. Doing so, it responds to the need for further development of a body of literature engaging with the perception of documents (Buckland 2014). In this paper we thus posit that Heider's concept of thing and medium is useful for making sense of how documents are simultaneously perceived as things and medium. We demonstrated that this conception can be employed for advancing conceptual understanding of documents by using it to investigate the role of Gantt charts in organizations and for looking at the concept of boundary objects.

\section{References}

Adamiecki, K. (1909). "Metoda wykreślna organizowania pracy zbiorowej w walcowniach", Przegl d Techniczny (17/18/19/20).

Baecker, D. (2002). "Beobachtung mit Medien", In Medien in Medien. C. Liebrand, and I. Schneider (Eds.) Köln: DuMont, 12-24.

Beniger, J. R. (1986). The Control Revolution. Cambridge, MA: Harvard University Press.

Boell, S. K.; Cecez-Kecmanovic, D. (2015). On Being 'Systematic' in Literature Reviews in IS. Journal of Information Technology 30(2), 161173.

Bowker, G. C., and Star, S. L. (1999). Sorting Things Out: Classification and its Consequences. Cambridge, MA: MIT Press.

Buckland, M. (2014). “Document Theory: An Introduction”, In Summer School on Records,

Chandler, A. D. Jr. (1977). The Visible Hand. The Managerial Revolution in American Business. Cambridge, MA: Harvard University Press.

Forbes-Pitt, K. (2006). “A Document for Document's Sake: A Possible Account for Document System Failures and A Proposed Way Forward", Records Management Journal 16(1), 13-30.

Freeman, R., and Maybin, J. (2011). "Documents, Practices and Policy", Evidence and Policy 7(2), 155-170.

Gantt, H. L. (1903). "A Graphical Daily Balance in Manufacture”, Transactions of the American Society of Mechanical Engineers 24, 1322-1336.

Gantt, H. L. (1919). Work, Wages, and Profits. [1910] New York: The Engineering Magazine Co.

Gibson, J. J. (1977). "The Theory of Affordances", In Perceiving, Acting, and Knowing. R. Shaw and J. Bransford (Eds.) Hillsdale: Lawrence Erlbaum Associates, 67-82.

Heider, F. (1926). "Ding und Medium”, Symposion, Philosophische Zeitschrift for Forschung und Aussprache 1, 109-157. 
Heider, F. (1944). "Social Perception and Phenomenal Causality", Psychological Review 51(6), 358-374.

Hoof, F. (2011). "Ist jetzt alles Netzwerk? Mediale 'Schwellen- und Grenzobjekte", In Jenseits des Labors. Transformationen von Wissen zwischen Entstehungs- und Anwendungskontext. F. Hoof, E.-M. Jung and U. Salascheck (Eds.) Bielefeld: Transcript, 45-62.

Hoof, F. (2015a). Engel der Effizienz: Eine Mediengeschichte der Unternehmensberatung. Konstanz: Konstanz University Press.

Hoof, F. (2015b). "The Media Boundary Objects Concept: Theorizing Film and Media”, In MediaMatter: The Materiality of Media, Matter as Medium. B. Herzogenrath (Ed.) New York and London: Bloomsbury, 180-200.

Hoof, F. (2016). "Medien managerialer Entscheidung: Decision-Making 'At a Glance", Soziale Systeme, forthcoming.

Hughes, J., and King, V. (1993). COMIC, working paper, available at: http://is.lse.ac.uk/staff/ sorenson/internet/html/download.html

Kelley, J. E., and Morgan A. W. (1959). "Critical-Path Planning and Scheduling", Proceedings of the Eastern Joint Computer Conference 16, 160-173.

Levy, D. M. (2001). Scrolling Forward: Making Sense of Documents in the Digital Age. New York: Arcade.

Luhmann, N. (1990). Die Wissenschaft der Gesellschaft. Frankfurt am Main: Suhrkamp.

Lund, N. W. (2009). Document Theory. Annual Review of the Information Science and Technology 43(1), 1-55.

Malcolm, D. G., Roseboom, J. H., Clark, C. E., and Fazar W. (1959). "Application of a Technique for Research and Development Program Evaluation", Operations Research 7(5), 646-669.

Marsh, E. R. (1975). "The Harmonogram of Karol Adamiecki", The Academy of Management Journal 18(2), 358-364.

McNurlin, B.C., and Sprague, R.H. Jr. (1998). Information Systems Management in Practice. 4th ed., Prentice-Hall: London.

Prior, L. (2008). "Repositioning Documents in Social Research", Sociology 42(5), 821-836.

Shillingsburg, P. (1991). "Text as Matter, Concept, and Action", Studies in Bibliography 44, 31-82.

Star, S. L. (1989). "The Structure of Ill-Structured Solutions: Boundary Objects and Heterogeneous Distributed Problem Solving", In Distributed Artificial Intelligence (Vol. 2). L. Gasser and M. N. Huhns (Eds.) London: Pitman, 3754.

Star, S. L. (2010). "This Is Not a Boundary Object: Reflections on the Origin of a Concept", Science, Technology and Human Values 35, 601-617.

Star, S. L., and Bowker, G. C. (2010). "How to Infrastructure." In Handbook of New Media: Social Shaping and Social Consequences of ICTs. L. A. Lievrouw, S. and Livingstone (Eds.) Updated Student Edition, London: Sage Publications, 230-246. 
Wright, A. (2007). Glut: Mastering Information Through the Ages. London: Cornell University Press.

Yakura, E. K. (2002). "Charting Time: Timelines as Temporal Boundary Objects." The Academy of Management Journal 45(5), 956-970.

Yates, J. (1989). Control through Communication. The Rise of System in American Management. London: John Hopkins University Press. 